\title{
High amplitude Theta wave bursts: a novel electroencephalographic feature of REM sleep and cataplexy
}

\author{
V. LO MARTIRE, S. BASTIANINI, C. BERTEOTTI, A. SILVANI, G. ZOCCOLI \\ PRISM lab, Department of Biomedical and Neuromotor Sciences, Alma Mater Studiorum, University \\ of Bologna, Bologna, Italy
}

Each author discloses the absence of any conflict of interest.

\begin{abstract}
A B S T R A C T
High amplitude theta wave bursts (HATs) were originally described during REMS and cataplexy in ORX-deficient mice as a novel neurophysiological correlate of narcolepsy (Bastianini et al., 2012). This finding was replicated the following year by Vassalli et al. in both ORX-deficient narcoleptic mice and narcoleptic children during cataplexy episodes (Vassalli et al., 2013). The relationship between HATs and narcolepsy-cataplexy in mice and patients indicates that the lack of ORX peptides is responsible for this abnormal EEG activity, the physiological meaning of which is still unknown. This review aimed to explore different phasic EEG events previously described in the published literature in order to find analogies and differences with HATs observed in narcoleptic mice and patients. We found similarities in terms of morphology, frequency and duration between HATs and several physiological (mu and wicket rhythms, sleep spindles, saw-tooth waves) or pathological (SWDs, HVSs, bursts of polyphasic complexes EEG complexes reported in a mouse model of CJD, and BSEs) EEG events. However, each of these events also shows significant differences from HATs, and thus cannot be equaled to them. The available evidence thus suggests that HATs are a novel neurophysiological phenomenon. Further investigations on HATs are required in order to investigate their physiological meaning, to individuate their brain structure(s) of origin, and to clarify the neural circuits involved in their manifestation.
\end{abstract}

\author{
Key words \\ Electroencephalography $\bullet$ Theta $\bullet$ Bursts $\bullet$ REMS $\bullet$ Narcolepsy $\bullet$ Cataplexy
}

\section{Introduction}

The loss of hypothalamic neurons releasing orexin peptides (ORX, A and B, also called hypocretins, 1 and 2, HCRT) leads to narcolepsy with cataplexy. Narcolepsy is characterized by the inability to maintain vigilance states, pathological intrusion of rapid eye movement sleep (REMS) and/or non-rapid eye movement sleep (NREMS) into wakefulness, and frequent transitions between states of sleep and wakefulness, which indicates that ORX have an important role in the stabilization of sleep and wakefulness (Sakurai, 2007). Cataplexy, sleep paralysis, hypnagogic (sleep-onset) hallucinations, and sleep onset REMS periods may be considered as abnormal REMS manifestations (Scammell, 2003). Cataplexy is a specific clinical trait in narcolepsy and is the best diagnostic marker of the disease, characterized by a sudden drop of muscle tone triggered by emotional factors, most often by positive emotions such 
as laughter, jokes, pleasant surprise, or by anger, but almost never by stress, fear, or physical effort. All striated muscles with exception for the diaphragm can be affected and may cause the individual to collapse (Dauvilliers et al., 2007). The duration of cataplexy varies from seconds to minutes and its frequency varies from less than one episode per year to several episodes per day. Cataplexy worsens with poor sleep and fatigue. There is neurophysiological and pharmacological evidence that cataplexy shares common neurophysiological mechanisms with REMS atonia (Dauvilliers et al., 2007).

Well-characterized mouse models of narcolepsy with cataplexy have been produced with deletion of the prepro-HCRT gene (KO, Chemelli et al., 1999) and with transgenic expression of a toxic protein that selectively kills the ORX-producing neurons (HCRT/ataxin 3 transgenic mice, TG, Hara et al., 2001). These mice show cataplexy-like behavioral arrests, occasional direct transition to REMS from wakefulness, poor maintenance of wakefulness, and fragmented sleep (Chemelli et al., 1999; Sakurai, 2007). The "International Working Group on Rodent Models of Narcolepsy" established a consensus definition of the features of murine cataplexy, expressing the confidence that it resembles human cataplexy closely enough for the term "murine cataplexy" to be appropriate (Scammell et al., 2009). Murine cataplexy was defined as an abrupt episode of neck muscle atonia lasting at least $10 \mathrm{sec}$, during which the mouse is immobile. During the episode, theta activity dominates the EEG and at least $40 \mathrm{sec}$ of wakefulness precede the episode. In the absence of concomitant video recordings proving immobility, these events are termed cataplexy-like episodes (CLE) (Scammell et al., 2009).

Recently, we have described the occurrence of a novel electroencephalographic (EEG) anomaly during REMS and CLE in ORX-deficient narcoleptic mice of different age, which we have named highamplitude theta wave bursts (HATs) (Bastianini et al., 2012; Silvani et al., 2014), (Figure 1; table I). Considering the paucity of information on this recently-discovered EEG feature, the present paper aims to review the similarities and the differences among HATs and other EEG phasic events described in normal EEG patterns, in narcolepsy with cataplexy and in other diseases, such as epilepsy and neurodegenerative diseases.

\section{HATs: high-amplitude bursts of theta waves during rapid-eye-movement sleep and cataplexy in orexin-deficient narcoleptic mice}

We described HATs as trains of at least three pointed waves clearly standing out against contiguous EEG activity and lasting $>0.5 \mathrm{sec}$. HATs were short, generally lasting 1-2 sec, had median frequency of 7 $\mathrm{Hz}$, and were significantly more likely to occur during the dark period than during the light period and at the end (i.e. last third) than at the beginning (i.e. first third) of REMS episodes. EMG tone slightly decreased during HATs. Finally, HATs were not associated with significant cardiovascular changes in terms of either systolic blood pressure or heart period (Bastianini et al., 2012).

Our study was the first to identify HATs as a distinct EEG phasic event associated with narcolepsy and cataplexy and to subject it to a thorough quantitative analysis (Bastianini et al., 2012). Phasic EEG events had already been noted as side-findings in ORX-deficient mice during cataplexy by other research groups (Chemelli et al., 1999; Hara et al., 1999; Willie et al., 2003). Due to the lack of detailed analyses and/or images in these precious reports, however, the correspondence between these events and HATs is uncertain. In particular, Chemelli et al. (1999) described phasic high amplitude EEG events in ORX-KO mice at the onset of abrupt behavioral arrests on a slow-wave or NREMS EEG background and interpreted them as sleep spindles (Chemelli et al., 1999). However, in ORX-KO mice, these events occurred immediately after a period of wakefulness in contrast to wild-type mice, in which sleep spindles were displayed typically only during the pre-REMS phase. The presence of pre-REMS spindles at sleep onset was interpreted as a further proof of abnormalities in the processes of REMS initiation in ORX-KO mice (Chemelli et al., 1999). Later, Hara et al. (2001) reported the occurrence of EEG phasic events during cataplexy episodes in TG mice (Hara et al., 1999) and Willie at al. (2003) observed these phenomena in more abrupt behavioural arrests, which appeared as sleep-onset REMS episodes (Willie et al., 2003). Again, the phasic EEG events described above were interpreted as a displacement of sleep spindles, which physiologically occurred during pre-REMS stage, but were not quantitatively described. Finally, Anaclet et al. (2010) reported preliminary evidence of episodes of EEG hypersynchronization during 


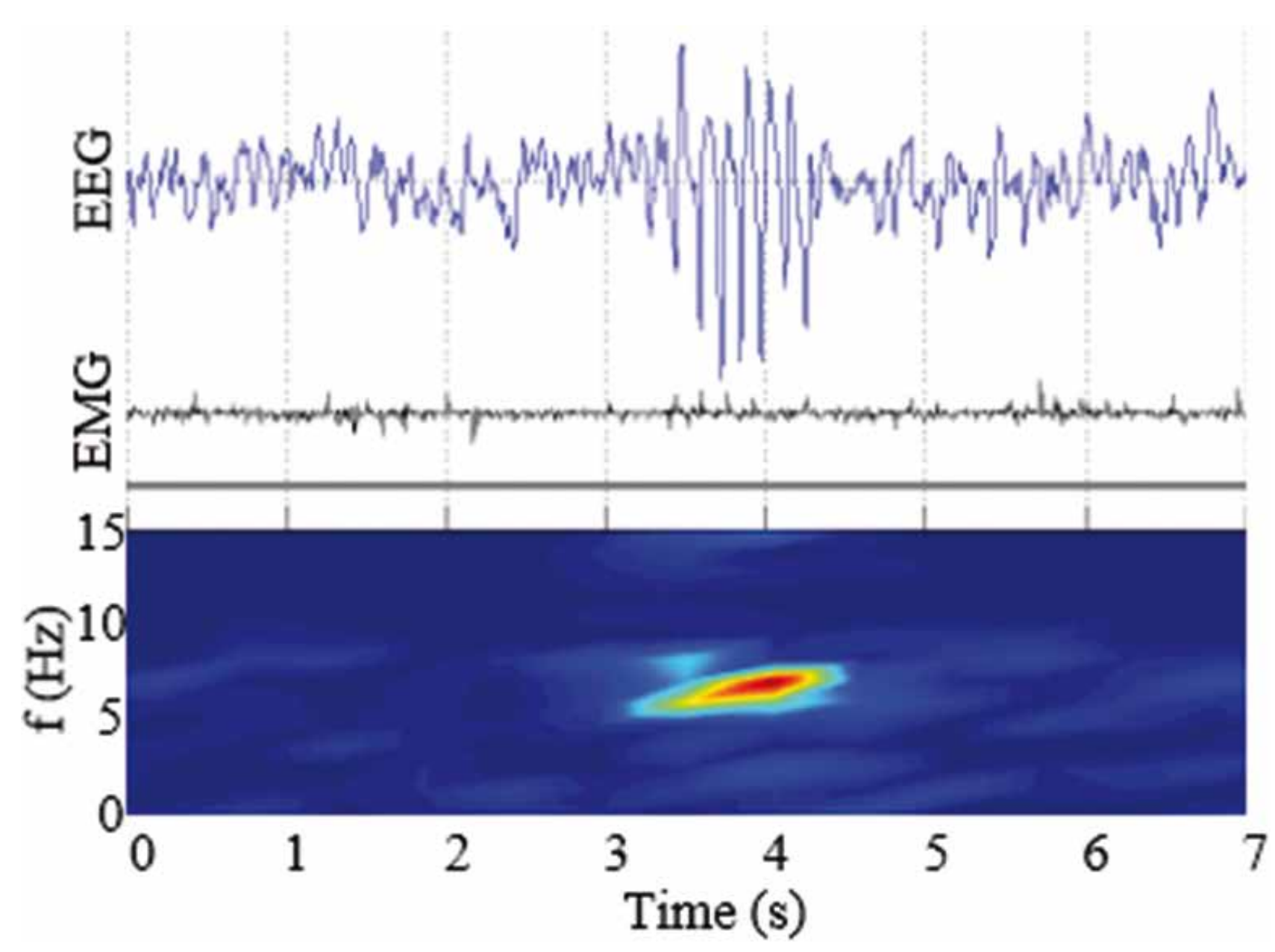

Fig. 1. - Representative recordings of a HAT event in a middle-aged TG mouse. Tracings show electroencephalogram (EEG) and nuchal muscles electromyogram (EMG). The lower part of the figure shows the EEG spectral power (false colours, with red indicating the higher values in the panel) as a function of frequency (f) and time. Reproduced from Silvani et al. (2014), with permission.

wakefulness and cataplexy in double $\mathrm{KO}$ mice lacking both histamine and ORX peptides (Anaclet et al., 2010). After our original description (Bastianini et al., 2012), HATs have been thoroughly analyzed by Vassalli et al. (2013) during cataplexy in TG and KO ORXdeficient mice (Bastianini et al., 2012; Vassalli et al., 2013). These authors called HATs hypersynchronous paroxysmal theta bursts, and defined them as conspicuous, stereotypical, high-amplitude theta EEG burst, with a relatively pure frequency of $7 \mathrm{~Hz}$ and a duration of 1.5-2 sec (Figure 2, panel e; table I). Spectral analysis showed a surging theta power at $7 \mathrm{~Hz}$, with up to four harmonic peaks at 14, 21, 28 and $35 \mathrm{~Hz}$. Interestingly, in this study, a novel distinct state was classified and scored as cataplexy-associated state (CAS) in ORX-deficient animals. CAS was defined as highly irregular, high-amplitude mixed delta/theta
EEG oscillations, with a visible dominance of theta over delta oscillations and low EMG activity. CAS was different from NREMS because of theta power dominance in the EEG, and different from REMS because a highly irregular and larger EEG amplitude. CAS frequently displayed a 1.5-2 sec theta burst phasic pattern, reminiscent of HATs but lacking their highly regular pattern, suggesting that CAS consisted of HATs mixed with other signals (Vassalli et al., 2013). CAS represented only $1 \%$ of the $12 \mathrm{~h}$ dark period and occupied $32 \%$ of time in cataplexy. Similarly, $46 \%$ of HATs occurred in epochs scored as cataplexy, being 16-fold more frequent during cataplexy than during any other time of the dark period (Vassalli et al., 2013). In order to define the brain site of origin of HATs and CAS, electrodes for depth EEG recording were implanted in various locations of mice 


\begin{tabular}{|c|c|c|c|}
\hline EEG events & Species & $\begin{array}{l}\text { Frequency } \\
(\mathrm{Hz})\end{array}$ & Definition \\
\hline $\begin{array}{l}\text { Hypersynchronous paroxys- } \\
\text { mal theta bursts (Vassalli et } \\
\text { al. 2013) }\end{array}$ & Human & $3-5$ & $\begin{array}{l}\text { a conspicuous, stereotypical, high-amplitude theta EEG } \\
\text { burst, with a duration of } 1.5-2 \text { sec, not observed in normal } \\
\text { paradoxical sleep or in adult cataplexy recordings }\end{array}$ \\
\hline $\begin{array}{l}\text { Saw-tooth waves } \\
\text { (Sato et al. 1997) }\end{array}$ & Human & $2-6$ & $\begin{array}{l}\text { trains of sharply contoured or triangular, often serrated waves } \\
\text { maximal in amplitude over the central head regions and of- } \\
\text { ten, but not always, preceding a burst of rapid eye movements }\end{array}$ \\
\hline $\begin{array}{c}\mu \text { rhythm } \\
(\text { Stern 2013) }\end{array}$ & Human & $7-11$ & $\begin{array}{l}\text { regularly repeating waves that alternate between sharply } \\
\text { contoured phases and rounded phases }\end{array}$ \\
\hline $\begin{array}{l}\text { Wicket rhythm } \\
\text { (van Sweden et al. 1999) }\end{array}$ & Human & $6-11$ & $\begin{array}{l}\text { repetitions of monophasic waves with alternating sharply } \\
\text { contoured and rounded phases }\end{array}$ \\
\hline $\begin{array}{l}\text { SWDs } \\
\text { (Stern 2013) }\end{array}$ & Human & 3 & $\begin{array}{l}\text { regular, symmetrical, generalized and transient electroen- } \\
\text { cephalographic patterns seen in many types of epilepsy, } \\
\text { and particularly in typical absence seizure }\end{array}$ \\
\hline $\begin{array}{c}\text { HATs } \\
\text { (Bastianini et al. 2012) }\end{array}$ & Mouse & 7 & $\begin{array}{l}\text { trains of three pointed waves clearly standing out against } \\
\text { contiguous EEG activity and lasting }>0.5 \mathrm{sec}\end{array}$ \\
\hline $\begin{array}{l}\text { Hypersynchronous paroxys- } \\
\text { mal theta bursts (Vassalli et } \\
\text { al. 2013) }\end{array}$ & Mouse & 7 & $\begin{array}{l}\text { a conspicuous, stereotypical, high-amplitude theta EEG } \\
\text { burst, with a duration of } 1.5-2 \mathrm{sec}\end{array}$ \\
\hline $\begin{array}{l}\text { Pre-REMS splindles (Vyazovs- } \\
\text { kiy et al. 2004) }\end{array}$ & Mouse & 11 & $\begin{array}{l}\text { spikes bursts occurring during the light period and at the } \\
\text { beginning of REMS episodes }\end{array}$ \\
\hline $\begin{array}{c}\text { SWDs } \\
\text { (Drinkenburg et al. 1993) }\end{array}$ & Rat & $7-11$ & $\begin{array}{l}\text { regular, symmetrical, generalized and transient electroen- } \\
\text { cephalographic patterns seen in genetic absence epileptic } \\
\text { rats strains occurring mainly during wakefulness and NREMS }\end{array}$ \\
\hline $\begin{array}{l}\text { HVSs } \\
\text { (Sales-Carbonell et al. 2013; } \\
\text { Radek et al. 1994) }\end{array}$ & $\begin{array}{l}\text { Mouse } \\
\text { Rat }\end{array}$ & $\begin{array}{l}5 \\
8\end{array}$ & $\begin{array}{l}\text { oscillatory bursts with a shape, frequency, length }(\sim 1-2 \mathrm{sec}) \text {, } \\
\text { and amplitude ( }>0.5 \mathrm{mV}) \text {, similar to SWD seizures. } \\
\text { In rats associated to memory impairment and progression of } \\
\text { brain dysfunction (lasting } 5 \mathrm{sec} \text { ) }\end{array}$ \\
\hline $\begin{array}{l}\text { CJD abnormal EEG activity } \\
\text { (Dossena et al. 2008) }\end{array}$ & Mouse & $7-8$ & $\begin{array}{l}\text { bursts of polyphasic complexes lasting from } 0.3 \text { to } 4.6 \mathrm{sec} \text {, } \\
\text { with a variable amplitude }\end{array}$ \\
\hline $\begin{array}{l}\text { BSEs } \\
\text { (Ryan 1984) }\end{array}$ & Mouse & $6-7$ & $\begin{array}{l}\text { episodes occurring during active waking with a duration of } \\
1.5-2 \mathrm{sec} \text {, a pointed morphology and a high amplitude }\end{array}$ \\
\hline
\end{tabular}

brain. Since in rodents EEG theta rhythm is originated in the hippocampus (Buzsaki, 2002), HATs and CAS may have been expected to have hippocampal origin. Conversely, HATs and CAS were found to be prominent in frontal EEG, and easily recorded by depth electrodes implanted in prefrontal cortex, thus suggesting an extra-hippocampal origin of these events. The fine mapping of these sites of origin with dense sets of electrodes awaits experimental investigation.

\section{Hypersynchronous paroxysmal theta during cataplexy in narcoleptic children}

A key contribution of Vassalli et al. (2013) was to describe in narcoleptic children the occurrence of phasic EEG events akin to HATs (Vassalli et al.,
2013). HATs were not observed in adult narcoleptic patients. In narcoleptic children, cataplexy was characterized by frequent runs of alpha EEG oscillations and regular theta EEG oscillations. HATs in narcoleptic children were similar to those observed in ORX-deficient narcoleptic mice but with a much slower peak frequency of 3-5 Hz, which ranged between the upper delta and the lower theta frequency ranges (Figure 2, panel a; table I). Vassalli et al. (2013) noted that the lower HAT peak frequency in narcoleptic children than in mouse models of narcolepsy parallels a difference in the frequency range of the spike-wave-discharges (SWDs) typical of absence seizure $(2.5-4.0 \mathrm{~Hz}$ in human patients vs. $7-9 \mathrm{~Hz}$ in mice) (Vassalli et al., 2013). Moreover, the human hippocampus generally exhibits slow oscillations at 1-4 Hz, which share functional properties with the 

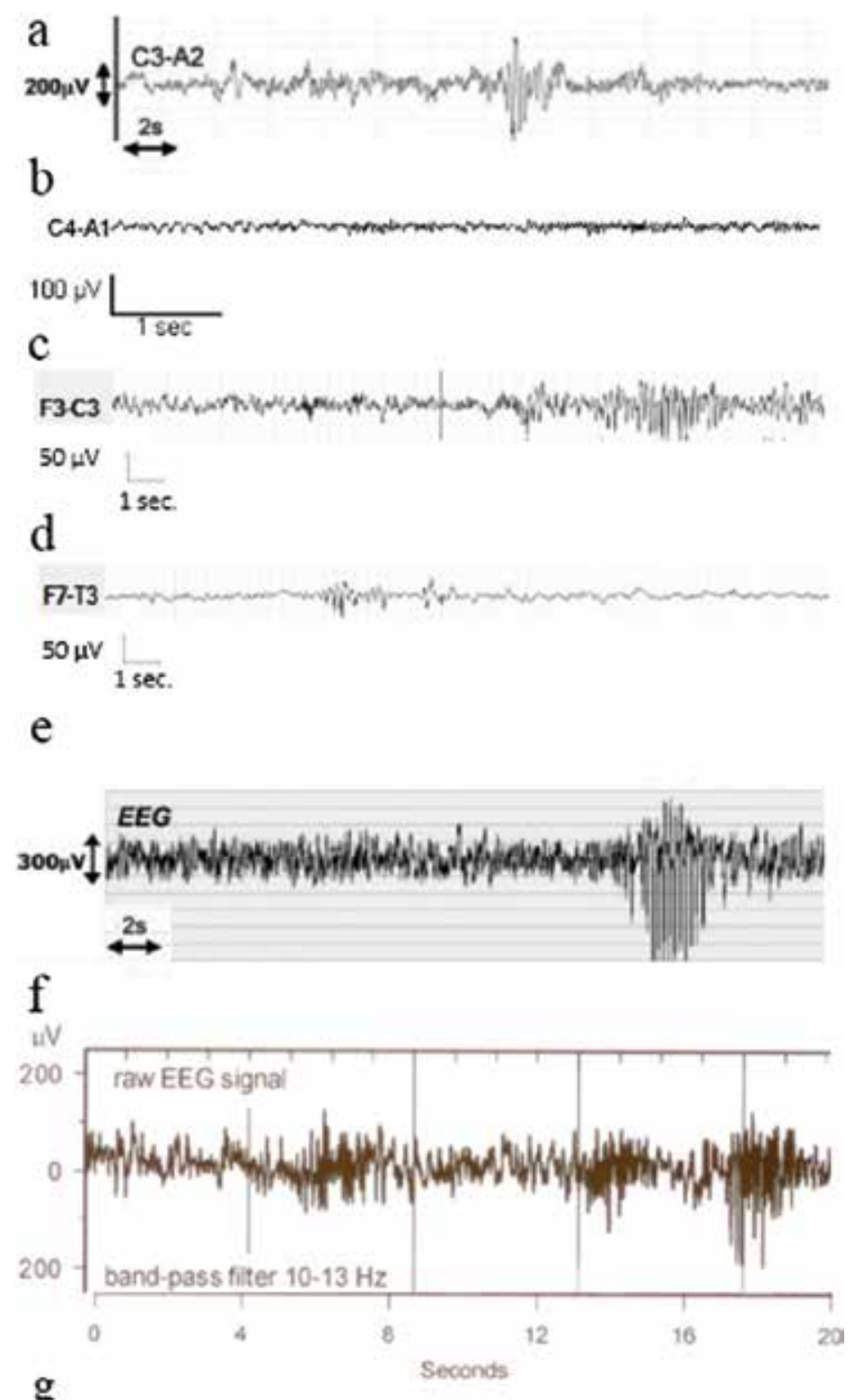

g

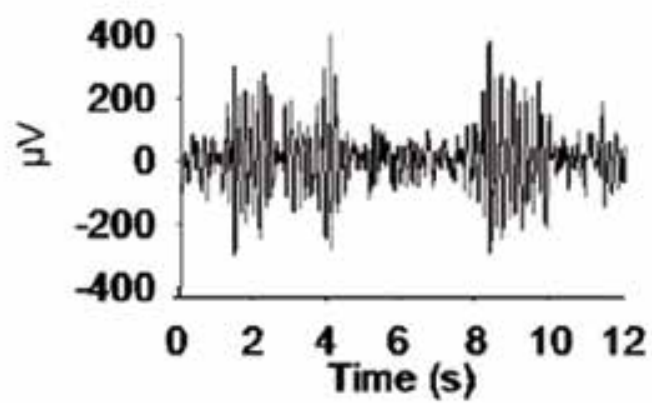

Fig. 2. - Representative EEG events resembling HATs in humans (panel a-d) and animals (panel e-g). Panel a: highamplitude theta EEG burst in narcoleptic children. Reproduced from Vassalli et al. (2013), with permission. Panels b: saw-tooth waves; panel c: $\mu$ rhythm; panel d: wicket rhythm; (courtesy of Dr. Lara Alvisi, EEG laboratory, IRCCS, Institute of Neurological Sciences, Bologna and Department of Biomedical and Neuromotor Sciences University of Bologna). Panel e: Hypersynchronous paroxysmal theta bursts (HPTS) in narcoleptic mice. Reproduced from Vassalli et al. (2013). Panel f: pre-REMS spindles in mice. Reproduced from Vyazovskiy et al. (2004), with permission. Panel g: EEG abnormal activity in a mouse model of CJD (courtesy of Prof. Luca Imeri, Department of Health Sciences University of Milan). 
rodent 4-8 Hz hippocampal theta rhythm, such as the maximal amplitude during REMS (Jacobs, 2014).

\section{Similarities and differences between HATs and phasic electroencephalographic events in physiological conditions in humans}

Physiological EEG recordings can show rhythms, like the mu and wicket rhythms, as well as EEG events typical of specific behavioral states such as sleep spindles and saw-tooth waves, which in some respects resemble HATs.

The mu rhythm is a physiological EEG rhythm in human subjects, particularly in young adults and females (Figure 2, panel c; table I). The mu rhythm comprises regularly repeating waves alternating between sharply contoured phases and rounded phases. Although the frequency of the mu rhythm is usually $7 \mathrm{~Hz}$, it can occur in the range between 7 to $11 \mathrm{~Hz}$ in human subjects (Stern, 2013). This rhythm is thought to occur only during wakefulness (Stern, 2013), when it is blocked by motor activity and is inhibited by the observation of effector-object interactions, suggesting a link with the mirror neuron system described in monkeys (Muthukumaraswamy et al., 2004). The wicket rhythm is a 6 to $11 \mathrm{~Hz}$ repetition of monophasic waves with alternating sharply contoured and rounded phases. This arciform appearance is similar to the mu rhythm (Stern, 2013), (Figure 2, panel d; table I). Wicket spikes are seen over the temporal regions, either bilaterally or independently over the two hemispheres (van Sweden et al., 1999). The wicket rhythm is a normal variant of physiologic EEG, and is usually found during light NREMS or drowsiness. Gelisse et al. (2003) reported that wicket spikes usually disappear during deep NREMS and re-appear during REMS with a similar morphology and at slightly lower amplitude (Gelisse et al., 2003). Recently, Serafini et al. (2014) confirmed activation of wicket spikes by REMS (Serafini et al., 2014). However, the mu rhythm in humans has also been reported to occur during REMS, and to be inhibited by somatosensory stimulation in this state (Duntley et al., 2001).

Thus, the mu and wicket rhythms bear some similarity to HATs (Bastianini et al., 2012) in terms of shape, frequency, and occurrence in REMS, raisin. This raises the hypothesis that HATs represent the pathological exacerbation of mu and/or wicket rhythms in ORX-deficient narcoleptic individuals. However, the human mu rhythm reaches its adult frequency range by 2 years of age (reviewed in Stern, 2013), which contrasts with the slower frequency of HATs reported by Vassalli et al. in narcoleptic children aged 8-11 years (Vassalli et al., 2013).

Saw-tooth waves are EEG events characteristic of REMS in human subjects but their source and function are still unknown. Saw-tooth waves are defined by consensus as trains of sharply contoured or triangular, often serrated, $2-6 \mathrm{~Hz}$ waves maximal in amplitude over the central head regions and often, but not always, preceding a burst of rapid eye movements (Silber et al., 2007), (Figure 2, panel b; table I). Although muscle tone changes during REMS usually precede the first saw-tooth wave, muscle tone reduction and saw-tooth waves occur more or less simultaneously (Sato et al., 1997). Saw-tooth waves thus differ from HATs because of their slower frequency (2-6 Hz for saw-tooth waves vs $7 \mathrm{~Hz}$ for HATs) and the occurrence at the beginning (saw-tooth waves) rather than at the end (HATs) of REMS episodes. Yet, the pointed shape and the slight decrease in EMG tone that characterize saw-tooth waves are analogous to those of HATs (Bastianini et al., 2012).

To summarize, the mu and wicket rhythms, sleep spindles, and saw-tooth waves each share some aspects with HATs (Table I) but none of them can be considered identical to HATs.

\section{Similarities and differences between HATs and phasic electroencephalographic events in physiological conditions in animals}

Physiological EEG recordings in different animal species can show EEG events typical of specific behavioral states similar to HATs concerning some of their aspects.

In rats, for example, a rhythm at a frequency of 7-12 $\mathrm{Hz}$ has been reported during immobile wakefulness and REMS and interpreted as analogous to the human mu rhythm (Marini et al., 2008).

Vyazovskiy et al. (2004) performed a quantitative analysis of sleep EEG spindles in C57B1/6 mice, showing that spindles were prominent during NREMS and during NREMS-REMS transitions, with a dominant frequency approximately at $11 \mathrm{~Hz}$ (Vyazovskiy et al., 
2004) and greater rate of occurrence at the end of the light period (Figure 2, panel f; table I). After 6-h of sleep deprivation protocol, the spindles in NREMS were initially suppressed, whereas the pre-REMS spindles were enhanced during the first 2 hours of recovery, suggesting a role of the former in the maintenance of sleep and of the pre-REMS spindles in REMS initiation (Vyazovskiy et al., 2004). Sleep spindles differ from the HATs described by Bastianini et al. (2012) in terms of EEG frequency ( $11 \mathrm{~Hz}$ for spindles vs. 7 $\mathrm{Hz}$ for HATs), the more frequent occurrence during the light (spindles) than during the dark (HATs) period and at the beginning (spindles) than at the end (HATs) of REMS episodes, and the association with cataplexy (Bastianini et al., 2012; Vyazovskiy et al., 2004).

\section{Similarities and differences between HATs and phasic electroencephalographic events in other human diseases}

Spikes are EEG transients, clearly distinguished from background activity, with duration between 20 ms and $70 \mathrm{~ms}$ (Stern, 2013). Spike-wave discharges (SWDs) are regular, symmetrical, generalized, and transient EEG patterns seen in many types of epilepsy and particularly in typical absence seizure (Stern, 2013), which is characterized by abrupt and brief impairments of consciousness (Table I). The destruction of the reticular thalamic nucleus has been shown to abolish SWDs (Meeren et al., 2009), suggesting a thalamic origin of SWDs. ORX peptides may play a key role in altering the firing mode of thalamic neurons associated with different states of consciousness, causing a shift from a burst (typical of drowsiness, NREMS and pathophysiological conditions such as absence epilepsy) to a tonic firing mode (typical of REMS) (Govindaiah and Cox, 2006). In humans during absence seizure, SWDs typically presents a slow frequency of about $3 \mathrm{~Hz}$ (Drinkenburg et al., 1993).

\section{Similarities and differences between HATs and phasic electroencephalographic events in animal models of other human diseases}

In genetic absence epileptic rat strains, the analogous of human SWDs occurs at frequencies of
7-11 Hz, with the same morphological aspects (Drinkenburg et al., 1993). Arain et al. (2012) showed that the haploinsufficiency of the $\alpha 1$ subunit of the GABAA receptor, which has been described in human absence epilepsy and juvenile myoclonic epilepsy, also causes epilepsy in mice, with absencelike seizures and interictal SWDs. These SWDs in mice are associated with attenuation of the EMG signal and behavioral arrests (Arain et al., 2012). Despite the analogy in morphology and peak frequency of HATs and SWDs, the most evident difference concerns the behavior-dependent occurrence of these EEG phenomena: SWDs occur mainly during wakefulness (47.8\%) and NREMS (47.9\%), but rarely during REMS (4\%) (Drinkenburg et al., 1993), (Table I). Interestingly, also activation of cannabinoid type 1 receptor (CB1) at striato-nigral synapses may induce hypersynchronous thalamocortical oscillations called high-voltage spindles (HVSs) with shape, frequency $(\sim 5 \mathrm{~Hz})$, duration $(\sim 1-2 \mathrm{sec})$, and amplitude $(>0.5 \mathrm{mV})$ resembling SWDs (Sales-Carbonell et al., 2013). Further studies during spontaneous wake-sleep behavior will needed to assess analogies and differences between these endogenous cannabinoid-mediated HVS and HATs (Table I).

Recently, an abnormal EEG pattern partially resembling HATs has also been described in a mouse model of the Creutzfeldt-Jakob disease (CJD), which expresses the mouse homolog of the D178N/ V129 prion protein (PrP), and thereby synthesizes a misfolded form of the mutant protein that is aggregated and protease-resistant (Dossena et al., 2008). As a result, these mice develop clinical and pathological features reminiscent of CJD, including motor dysfunction, memory impairment, cerebral PrP deposition, and gliosis. These mice also display EEG abnormalities and severe alterations of sleepwake patterns strikingly similar to those seen in a human affected patient (Dossena et al., 2008). The abnormal EEG activity of this mouse model of CJD is characterized by bursts of polyphasic complexes lasting from 0.3 to $4.6 \mathrm{sec}$, with peak frequency at $7-8 \mathrm{~Hz}$ and amplitude that may be larger than the EEG amplitude during NREMS (Figure 2, panel g; table I). Although these features do resemble those of HATs, the abnormal EEG activity observed in transgenic CJD mice differs from HATs in that they are equally distributed during the light and dark 
periods and occur in all behavioral states (Dossena et al., 2008).

Another EEG pattern similar to HATs was described in mice by Ryan et al. (1984) and called brief spindles episodes (BSEs) (Ryan, 1984). Like HATs, BSEs occur with a frequency of 6-7 Hz, a duration of 1.5-2 sec, a pointed morphology and a high amplitude (Ryan, 1984), (Table I). Interestingly, BSEs are facilitated by convulsant drugs, suggesting their classification as paroxysmal discharges (Ryan, 1984). However, BSEs differ from HATs in that they occur during wakefulness as opposed to REMS (Ryan, 1984).

The last pathological EEG pattern sharing some aspects with HATs was described in rats of different age by Radek et al. (1994). These spindles bursts were characterized by a pointed morphology, a 8 $\mathrm{Hz}$ frequency, and a $5 \mathrm{sec}$ duration (Table I). HVSs appeared more frequently in mature and aged rats, which reported a higher mean error score performing the Morris water maze test, thus suggesting an impairment of their spatial memory with age (Radek et al., 1994). HVSs discharges were interpreted by the authors as an electrophysiological change that parallels the progression of brain dysfunction associated with memory impairment (Radek et al., 1994). In literature, different cases of middle-age and elderly patients with HVS-like spindles epilepsy are reported, that present signs of dementia and confusion. The results obtained in rats suggest a possible involvement of this abnormal EEG activity with memory processes.

To summarize, as was the case for physiological EEG features, also SWDs, HVSs, bursts of polyphasic complexes EEG complexes reported in a mouse model of CJD, and BSEs resemble HATs in terms of morphology, frequency and duration (Table I), but none of them can be considered identical to HATs.

\section{Summary}

In 2012, high amplitude theta wave bursts (HATs) were originally described during REMS and cataplexy in ORX-deficient mice as a novel neurophysiological correlate of narcolepsy (Bastianini et al., 2012). This finding was replicated the following year by Vassalli et al. in both ORX-deficient narcoleptic mice and narcoleptic children during cataplexy episodes (Vassalli et al, 2013). The rela- tionship between HATs and narcolepsy-cataplexy in mice and patients indicates that the lack of ORX peptides is responsible for this abnormal EEG activity, the physiological meaning of which is still unknown. This review aimed to explore different phasic EEG events previously described in the published literature in order to find analogies and differences with HATs observed in narcoleptic mice and patients. We found similarities in terms of morphology, frequency and duration between HATs and several physiological (mu and wicket rhythms, sleep spindles, saw-tooth waves) or pathological (SWDs, HVSs, bursts of polyphasic complexes EEG complexes reported in a mouse model of CJD, and BSEs) EEG events. However, each of these events also shows significant differences from HATs, and thus cannot be equaled to them. The available evidence thus suggests that HATs are a novel neurophysiological phenomenon. One possibility that has yet to be explored is whether the dysfunction of other neurotransmitter systems is involved in the genesis of the HATs, in addition to that of ORX peptides. There are some evidences suggesting an involvement of histamine signalling.

ORX neurons widely project into the brain (Peyron et al., 1998), and in particular, densely innervate the tubero-mamillary nucleus (TMN) in the hypothalamus (Chemelli et al., 1999). ORX type 2 receptor are expressed in TMN (Marcus et al., 2001). Data obtained in narcoleptic patients and mice relative to the functionality of the histamine system are still controversial. Histamine levels in the cerebrospinal fluid of narcoleptic patients are reduced or unchanged compared to normal subjects (Dauvilliers et al., 2012; Kanbayashi et al., 2009) and the number of histamine neurons is increased or unchanged in ORX-deficient narcoleptic mice and human patients (John et al., 2013; Valko et al., 2013). At present, it is not possible to conclude whether the loss of ORX peptides control determines an effect on the neuronal production of histamine and on histamine discharge. Interestingly, Anaclet et al. (2010) reported episodes of EEG hypersynchronization during wakefulness and cataplexy in double KO mice lacking both histamine and ORX peptides (Anaclet et al., 2010). Moreover, preliminary results obtained in histidine-decarboxylase $\mathrm{KO}$ mice, lacking histamine, reported the occurrence of HATs during REMS (Zoccoli et al., 2014). Moreover, the same EEG events was described in WT mice after intracerebro- 
ventricular infusion of alpha-fluoromethyl-histidine, an inhibitor of the histamine-synthetizing enzyme.

Further investigations on HATs are required in order to investigate their physiological meaning, to individuate their brain structure(s) of origin, and to clarify the neural circuits involved in their manifestation.

\section{Acknowledgments}

The authors wish to thank Dr. Federica Provini and Dr. Lara Alvisi, EEG laboratory, IRCCS, Institute of Neurological Sciences, Bologna and Department of Biomedical and Neuromotor Sciences, University of Bologna and Prof. Luca Imeri, Department of Health Sciences University of Milano for the pictures that they kindly gave us.

\section{References}

Anaclet C., Ouk K., Guidon G., Buda C., Sastre J., Ohtsu H., Yanagisawa M., Franco P., Lin J. Complementary and Synergistic Control of Wakefulness by Orexins and Histamine, Demonstrated Using a Double Knockout Mouse Model. J. Sleep Res., 19: 154, 2010.

Arain F.M., Boyd K.L., Gallagher M.J. Decreased viability and absence-like epilepsy in mice lacking or deficient in the GABAA receptor alpha1 subunit. Epilepsia, 53: e161-165, 2012.

Bastianini S., Silvani A., Berteotti C., Lo Martire V., Zoccoli G. High-amplitude theta wave bursts during REM sleep and cataplexy in hypocretin-deficient narcoleptic mice. J. Sleep Res., 21: 185-188, 2012.

Buzsaki G. Theta oscillations in the hippocampus. Neuron, 33: 325-340, 2002.

Chemelli R.M., Willie J.T., Sinton C.M., Elmquist J.K., Scammell T., Lee C., Richardson J.A., Williams S.C., Xiong Y., Kisanuki Y., Fitch T.E., Nakazato M., Hammer R.E., Saper C.B., Yanagisawa M. Narcolepsy in orexin knockout mice: molecular genetics of sleep regulation. Cell, 98: 437-451, 1999.

Dauvilliers Y., Arnulf I., Mignot E. Narcolepsy with cataplexy. Lancet, 369: 499-511, 2007.

Dauvilliers Y., Delallee N., Jaussent I., Scholz S., Bayard S., Croyal M., Schwartz J.C., Robert P. Normal cerebrospinal fluid histamine and telemethylhistamine levels in hypersomnia conditions. Sleep, 35: 1359-1366, 2012.
Dauvilliers Y., Pennestri, MH., Petit, D, Dang-Vu T., Lavigne G., Montplaisir J. Periodic leg movements during sleep and wakefulness in narcolepsy. J. Sleep Res., 16: 333-339, 2007.

Dossena S., Imeri L., Mangieri M., Garofoli A., Ferrari L., Senatore A., Restelli E., Balducci C., Fiordaliso F., Salio M., Bianchi S., Fioriti L., Morbin M., Pincherle A., Marcon G., Villani F., Carli M., Tagliavini F., Forloni G., Chiesa R. Mutant prion protein expression causes motor and memory deficits and abnormal sleep patterns in a transgenic mouse model. Neuron, 60: 598-609, 2008.

Drinkenburg W.H., van Luijtelaar E.L., van Schaijk W.J., Coenen A.M. Aberrant transients in the EEG of epileptic rats: a spectral analytical approach. Physiol. Behav., 54: 779-783, 1993.

Duntley S.P., Kim A.H., Silbergeld D.L., Miller J.W. Characterization of the mu rhythm during rapid eye movement sleep. Clin. Neurophysiol., 112: 528-531, 2001.

Gelisse P., Kuate C., Coubes P., Baldy-Moulinier M., Crespel A. Wicket spikes during rapid eye movement sleep. J. Clin. Neurophysiol., 20: 345-350, 2003.

Govindaiah G., Cox C.L. Modulation of thalamic neuron excitability by orexins. Neuropharmacology, 51: 414-425, 2006.

Hara J., Beuckmann C.T., Nambu T., Willie, JT., Chemelli RM., Sinton, CM., Sugiyama F., Yagami K., Goto K., Yanagisawa M., Sakurai T. Genetic ablation of orexin neurons in mice results in narcolepsy, hypophagia, and obesity. Neuron, 30: 345-354, 2001.

Jacobs J. Hippocampal theta oscillations are slower in humans than in rodents: implications for models of spatial navigation and memory. Philos. Trans. R. Soc. Lond. B Biol. Sci., 369: 20130304, 2014.

John J., Thannickal T.C., McGregor R., Ramanathan L., Ohtsu H., Nishino S., Sakai N., Yamanaka A., Stone C., Cornford M., Siegel J.M. Greatly increased numbers of histamine cells in human narcolepsy with cataplexy. Ann. Neurol., 74: 786793, 2013.

Kanbayashi T., Kodama T., Kondo H., Satoh S., Inoue Y., Chiba S., Shimizu T., Nishino S. CSF histamine contents in narcolepsy, idiopathic hypersomnia and obstructive sleep apnea syndrome. Sleep, 32: 181-187, 2009.

Marcus J.N., Aschkenasi C.J., Lee C.E., Chemelli R.M., Saper C.B., Yanagisawa M., Elmquist J.K. Differential expression of orexin receptors 1 and 2 in the rat brain. J. Comp. Neurol., 435: 6-25, 2001. 
Marini G., Ceccarelli P., Mancia M. Characterization of the 7-12 Hz EEG oscillations during immobile waking and REM sleep in behaving rats. Clin. Neurophysiol., 119: 315-320, 2008.

Meeren H.K., Veening J.G., Moderscheim T.A., Coenen A.M., van Luijtelaar G. Thalamic lesions in a genetic rat model of absence epilepsy: dissociation between spike-wave discharges and sleep spindles. Exp. Neurol., 217: 25-37, 2009.

Muthukumaraswamy S.D., Johnson B.W., McNair N.A. Mu rhythm modulation during observation of an object-directed grasp. Brain Res. Cogn. Brain Res., 19: 195-201, 2004.

Peyron C., Tighe D.K., van den Pol A.N., de Lecea L., Heller H.C., Sutcliffe J.G., Kilduff T.S. Neurons containing hypocretin (orexin) project to multiple neuronal systems. J Neurosci., 18: 9996-10015, 1998.

Radek R.J., Curzon P., Decker M.W. Characterization of high voltage spindles and spatial memory in young, mature and aged rats. Brain. Res. Bull., 33: 183-188, 1994.

Ryan L.J. Characterization of cortical spindles in DBA/2 and C57BL/6 inbred mice. Brain. Res. Bull., 13: 549-558, 1984.

Sakurai T. The neural circuit of orexin (hypocretin): maintaining sleep and wakefulness. Nat. Rev. Neurosci., 8: 171-181, 2007.

Sales-Carbonell C., Rueda-Orozco P.E., SoriaGomez E., Buzsaki G., Marsicano G., Robbe D. Striatal GABAergic and cortical glutamatergic neurons mediate contrasting effects of cannabinoids on cortical network synchrony. Proc. Natl. Acad. Sci. U.S.A, 110: 719-724, 2013.

Sato S., McCutchen C., Graham B., Freeman A., von Albertini-CarlettiI.,Alling D.W.Relationshipbetween muscle tone changes, sawtooth waves and rapid eye movements during sleep. Electroencephalogr. Clin. Neurophysiol., 103: 627-632, 1997.

Scammell T.E., Willie, JT., Guilleminault C., Siegel, JM. A consensus definition of cataplexy in mouse models of narcolepsy. Sleep, 32: 111-116, 2009.

Scammell T.E. The neurobiology, diagnosis, and treatment of narcolepsy. Ann. Neurol., 53: 154166, 2003.
Serafini A., Crespel A., Velizarova R., Gelisse P. Activation of wicket spike by REM sleep. Neurophysiol. Clin., 44: 245-249, 2014.

Silber M.H., Ancoli-Israel S., Bonnet M.H., Chokroverty S., Grigg-Damberger M.M., Hirshkowitz M., Kapen S., Keenan S.A., Kryger M.H., Penzel T., Pressman M.R., Iber C. The visual scoring of sleep in adults. J. Clin. Sleep. Med., 3: 121-131, 2007.

Silvani A., Bastianini S., Berteotti C., Cenacchi G., Leone O., Lo Martire V., Papa V., Zoccoli G. Sleep and cardiovascular phenotype in middle-aged hypocretin-deficient narcoleptic mice. $J$. Sleep Res., 23 98-106, 2014.

Stern J. Atlas of EEG patterns. 2013, New York: Lippincoat Williams \& Wilkins.

Valko P.O., Gavrilov Y.V., Yamamoto M., Reddy H., Haybaeck J., Mignot E., Baumann C.R., Scammell T.E. Increase of histaminergic tuberomammillary neurons in narcolepsy. Ann. Neurol., 74: 794-804, 2013.

van Sweden B., Wauquier A., Niedermeyer E. Normal aging and transient cognitive disorders in the elderly. pp. 340-348. In: Niedermeyer E., and Lopes da Silva F. (Eds.) Electroencephalography, Basic Principles, Clinical Applications and Related Fields. Baltimore, Williams \& Wilkins, 1999.

Vassalli A., Dellepiane J.M., Emmenegger Y., Jimenez S., Vandi S., Plazzi G., Franken P., Tafti M. Electroencephalogram paroxysmal theta characterizes cataplexy in mice and children. Brain, 136: 1592-1608, 2013.

Vyazovskiy V.V., Achermann P., Borbely A.A., Tobler I. The dynamics of spindles and EEG slowwave activity in NREM sleep in mice. Arch. Ital. Biol., 142: 511-523, 2004.

Willie J.T., Chemelli R.M., Sinton C.M. Distinct narcolepsy syndromes in Orexin receptor-2 and Orexin null mice: molecular genetic dissection of Non-REM and REM sleep regulatory processes. Neuron, 38: 715-730, 2003.

Zoccoli G., Bastianini S., Berteotti C., Lin J.S., Lo Martire V., Ohtsu H., Silavni A. Theta wave bursts during rapid-eye-movement sleep in histaminedeficient mice. J. Sleep Res., 23: 319, 2014. 